\title{
THE PENTANE LAMP AS A WORKING STANDARD
}

\author{
By E. C. Crittenden and A. H. Taylor
}

\section{CONTENTS}

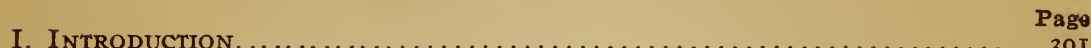

I. Purpose of paper.

2. Extent of use of pentane lamps . . . . . . . $\ldots \ldots \ldots \ldots \ldots$

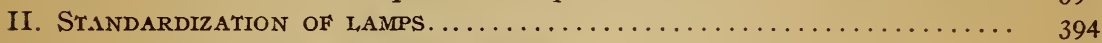

I. Necessity of photometric test. . . . . . . . . 394

2. Photometer room-Ventilation, screening, and apparatus...... 395

3. Adjustment of lamps........................ 396

4. Operation of lamps-Pentane, flame height, and time of burning. $\quad 398$

5. Basis of standardization. ........................ 400

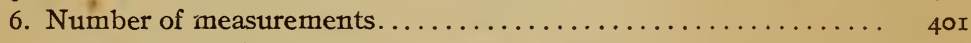

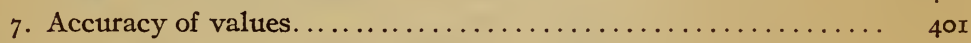

III. GENERAL, DIRECTIONS FOR USE OF PENTANE LAMPS . . . . . . . . 402

I. Ventilation and effects of vitiation of air............... 403

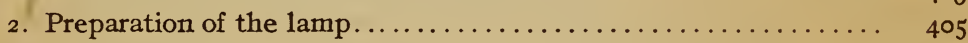

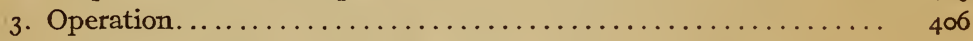

IV. PENTANE-PREPARATION, TESTING, AND USE................ 407

I. Preparation and testing........................ 407

2. Change during use and correction determined by density...... 408

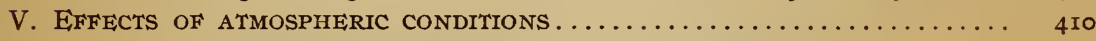

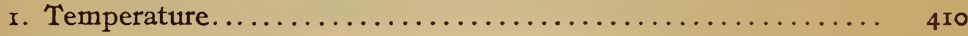

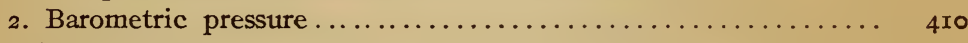

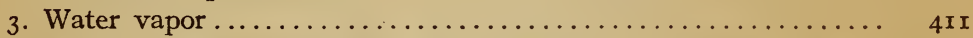

4. Chart of departures from normal value............... ${ }_{4} \mathrm{I}_{3}$

5. Variations of humidity in the United States............. $4 \mathrm{I} 5$

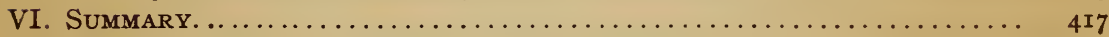

\section{INTRODUCTION}

\section{PURPOSE OF PAPER}

In the Transactions of the Illuminating Engineering Society there have already been published two papers ${ }^{1}$ dealing with the work on flame standards of candlepower which has been done at the Bureau of Standards. These papers were intended to be

1 Trans. Ill. Eng. Soc., 5, pp. 753-778, x9ro; and 6, pp. 41 7-432; 19r r. $35^{26} 5^{\circ}-\mathrm{x} 4-6$ 
particularly reports of progress in the experimental work which has been done on various types of lamps. The investigation of the lamps was made with the double purpose of determining whether any of them were capable of furnishing a check on a possible drift in the value of the unit now maintained by electric incandescent standards, and of finding a satisfactory working standard for use where electric standards are impracticable.

The results of that work proved to be distinctly favorable to the use of the Harcourt ro-candle pentane lamp as a secondary standard. Since the publication of the papers mentioned the use of such lamps has become much more extensive, and the present paper is written with a somewhat different object in view, namely, to cover the questions which have arisen regarding their operation. This involves a fullness of detail which may not be of much interest to the general reader, but which it nevertheless appears desirable to put in print because some of this information is not generally available. Directions for the use of these lamps in making tests of gas are issued by the Metropolitan Gas Referees of London, who developed this type of lamp. Their directions, however, are not entirely applicable to American practice, and in some respects the methods here described differ materially from theirs.

\section{EXTENT OF USE OF PENTANE LAMPS}

The number of pentane lamps tested by the Bureau is not an exact indication of the extent to which the use of the lamps has increased, because many have been standardized in other laboratories and many others, especially in the early years of their use, were not standardized at all. Nevertheless, the number tested by the Bureau as given in the statement below, is an indication of the widespread adoption of this standard.

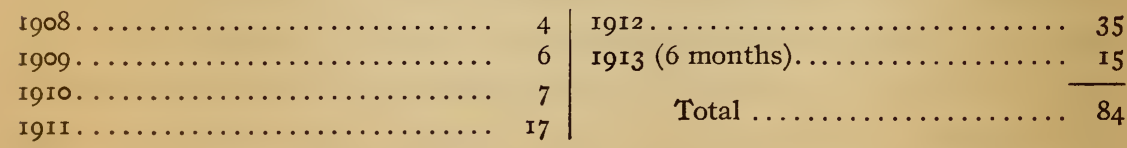

Since in many cases one of these lamps furnishes the basis on which the quality of the gas supply of a city, so far as candlepower 
is concerned, is judged, the importance of the pentane lamp in present practice will be appreciated.

While the lamp has found its widest use in gas testing, where a flame standard is preferred because the effects of atmospheric conditions on it compensate for similar effects on the gas flame, its usefulness is by no means limited to work of that kind. The corrections to determine the actual candlepower are easily made, and the lamp affords a fairly convenient method of obtaining a basic standard for laboratories which lack the batteries and accurate instruments which are necessary to get dependable values from electric standards.

In some cases the pentane lamp may thus serve as a basis of standardization even when it may be found more convenient to use other working standards for the actual tests. For example, when a series of measurements are made extending over several hours another source, such as a kerosene lamp, an Edgerton standard, or a gas mantle may be used as a constant comparison light at one end of the bar, its value being fixed by substituting a pentane lamp for the test flame or lamp at the beginning and the end of the series. An electric lamp kept at constant current may be used in the same way as a comparison light. This is exactly what is done in most portable photometers, and the calibration of such photometers can be based on a pentane lamp as well as on an electric standard. A modification of this practice, which is useful where tests for approximate values have to be made at a number of stations, is to provide for each station a portable standard unit consisting of a low-voltage lamp and a storage battery, the whole unit being brought in at regular intervals for recharging and recalibrating against the pentane standard. From a curve showing the variation in candlepower with time of use for such a unit one can obtain fairly satisfactory values without the use of either regulating resistances or electrical measuring instruments. The details of such a system in actual operation have recently been described. ${ }^{2}$ In using such standards, as in any case where electric lamps are compared with

${ }^{2}$ H. L. Farrar: Gas Age, 31, pp. 407-409 (Apr. 15); 1913. 
flames, the effects of humidity are important. The readings can, however, be easily corrected for this by the use of such a chart as is given in Fig. 3 .

It is hardly necessary to give here a long discussion of the relative advantages of different lamps and of the reasons which are leading to the common use of the pentane lamp as a working standard in this country. There are other lamps which may be used in cases where their value can be frequently checked or where the accuracy required is not great. In some other cases, especially where portability is an important consideration, the Hefner lamp is to be recommended; by making many measurements under favorable conditions very good results can be obtained with it, but in general its low candlepower, comparatively red light, extreme sensitiveness to drafts, and unsteadiness at temperatures above $70^{\circ} \mathrm{F}$. make it difficult to use. The pentane lamp has the disadvantages of being large and not easily portable, of using fuel which is expensive and somewhat dangerous, and of requiring more air than ordinary ventilation will supply. In spite of these faults its use is increasing, chiefly because it appears to be the only standard of candlepower now in use, other than incandescent electric lamps, which can be relied upon to give, under the usual working conditions, the degree of accuracy expected in present commercial practice.

\section{STANDARDIZATION OF LAMPS}

\section{NECESSITY OF PHOTOMETRIC TEST}

The necessity for standardization of each lamp by a photometric test arises from the fact that different lamps, even of the same maker and supposedly of the same type, show differences in candlepower which are sometimes as great as 4 per cent. The construction is such as to make it difficult to determine after a lamp is assembled whether it is built exactly according to specifications. In fact, exact adherence to specified dimensions might not remove the differences between lamps unless other conditions also were definitely specified. For example, the castings used in the American lamps have a rough inner surface; this roughness 
probably facilitates the transfer of heat to or from the air, and it may also affect slightly the flow of air through the passages. Whatever may be the cause of the differences between lamps, the candlepower of the individual lamp is the important thing, and the logical test is to determine the candlepower. In lamps tested at the Bureau details of construction are not given special attention unless some part is so made that it appears to be a possible cause of variation in the candlepower of the lamp.

Since the lamp itself is only an instrument for producing the actual standard, the flame, there is little significance in a value given for the lamp unless other factors, such as air and fuel, and other conditions of operation are known. The value certified for a lamp applies strictly only for its use under conditions identical with those under which it was standardized; it may, therefore, be worth while to particularize rather fully the method of testing followed at the Bureau.

\section{PHOTOMETER ROOM-VENTILATION, SCREENING, AND APPARATUS}

The photometer room used hitherto is approximately 26 by 18 by 12 feet. Ventilation is obtained by a tempered air heating system. The ordinary ventilation would not keep the air sufficiently pure if the flame gases were allowed to escape into the room, and consequently above the lamp is hung a hood 2 feet in diameter, with an outlet into one of the ventilating ducts. The draft into this hood is just strong enough to insure that all the gases rising from the lamp shall pass into the hood and thus be carried out of the room. This arrangement is so effective that no perceptible change in the candlepower of the lamps due to vitiation of the air occurs in several hours' continual burning. In regular work, however, the room is usually aired out at least once every hour.

The photometer room is in a corner of the building and often has troublesome drafts, in consequence of which it has been found that the performance of the lamps has been improved by screening them on three sides and sometimes on all four sides. This is done by a wooden framework about 3 feet long, 2 feet wide, and 3 feet high, carrying a strip of cloth which extends from the top of the 
frame down to 6 inches from the bottom, thus allowing free access of the air from all sides below the lamp but preventing any drafts from striking the flame or the circulatory system of the lamp directly. This screening was adopted after many trials of various forms of inclosure had shown that in most of them the lamps gave values slightly different from those obtained in the open, even when no vitiation of the air in the inclosure could be detected.

In special tests of the state of the air a Zeiss refractometer has been used to determine the quantity of $\mathrm{CO}_{2}$ present. Measurements of atmospheric moisture are regularly made with two Assmann psychrometers, and of pressure by a mercury barometer. The details of the calculation of the moisture will be given later, in connection with the corresponding corrections.

The photometer outfit is of the standard form regularly used at the Bureau, with Lummer-Brodhun contrast head and a recording device of which a description has been published. ${ }^{3}$ The substitution method with constant intensity on the disk is used as in all standard work-that is, a constant "comparison lamp" is connected to the photometer head at a fixed distance from it, while the electric "working standards" and the pentane lamps under test are alternately put in on the other side for reading.

\section{ADJUSTMENT OF LAMPS}

Before putting the lamp on the photometer the chimney is inspected by looking down through it to see that it is set centrally over the burner, and each time the lamp is lighted the gauge is applied to make sure that the chimney is at the proper heightthat is, $47 \mathrm{~mm}$ above the burner when cold. The chimney seldom has to be reset, but occasionally one creeps slightly with heating and cooling.

In setting up the lamp on the table care is taken to level it so that the chimney shall be vertical. The levels (plumb bobs on later lamps) attached for this purpose are not always exact, and this leveling is done by dropping a plumb line from the center of the top of the chimney, so that the bob should hang centrally in the

${ }^{2}$ G. W. Middlekauff, this Bulletin, 7, p. 18, rgro; and Elect. World, 56, p. I53, (July 21); rgro. 
burner. The height of the lamp is so adjusted that the middle of the flame is on a level with the center of the photometer disk. The directions of the Gas Referees are such as to bring the bottom of the chimney on a level with the center of the disk, and this setting makes the illumination on the disk follow the inverse square law more exactly than if the lamp is higher. The American Gas Institute's committee on taking candlepower of gas has, however, recommended the other position, and in order to avoid confusion the Bureau has followed this recommendation. The lamp is usually placed so that the axis of the photometer passes through the air tube as well as through the center of the burner and chimney. In some cases, however, on request, the lamps are turned $90^{\circ}$, so that a plane passing through the chimney and the air tube is at right angles to the photometric axis. No difference has been detected in the values obtained in the two positions for any lamp. In either case the chimney is so turned that the light from the mica window does not fall on the photometer disk or on the lamp standard or the pentane feed tube.

In measuring distances from the lamp the center of the burner is taken as the point of departure. The photometric observations are made at a distance of approximately $\mathrm{I}$ meter. For setting the lamp at the proper point on the scale it has been found convenient to follow the English method of using a rod having near one end a cylindrical plug which fits into the burner. This rod is made of such length that the other end just touches the photometer head when the center of the burner is I meter from the disk. This fixes very exactly the point of the scale which is I meter from the lamp, and a line on the record sheet is set at this point. The distance of the comparison lamp is then so chosen as to make the settings on the pentane lamp fall near the line, and in working up the sheet the distances of the groups of points which represent readings on the lamp are measured from this line. 
4. OPERATION OF LAMPS: PENTANE, FLAME HEIGHT, AND TIME OF BURNING

The pentane used is tested with respect to density and purity; the effects of possible variation in the fuel are so important that a later section of this paper is devoted particularly to that question.

The method of controlling the flame height has been the subject of considerable difference of opinion. At the Bureau no difference in candlepower has been found to result from the use of the various cocks at which regulation may be effected. Even wher the saturator is entirely closed off from the air, and the pressure of the vapor in it is allowed to run up to 9 inches of water, regulation of the flame height being made by a cock near the burner, no departure as great as I per cent from the normal candlepower occurs. In standardizing the older lamps, in which such cocks are provided, they have been used. The newer lamps do not have these cocks, and flame height is controlled by the outlet cock of the saturator, in which case greater ease of adjustment is obtained by clamping a lever on to the handle of the cock.

Another question concerning which there are differences of opinion is that of the proper flame height. In English lamps the top of the flame should be set at the middle of the lower mica window, about $27 \mathrm{~mm}$ above the bottom of the chimney. The lamps are so proportioned that with this height of flame the candlepower is near its maximum, and a small shift up or down makes very little change in candlepower. This is shown in curve $\mathrm{E}$ of Fig. I, where abscissas are candlepowers and ordinates are heights of flame in the chimney. The effect of personal error in judgment of height of flame is thus made very small.

The American makers have placed the crossbar of the window lower, and direct that the flame be set with the tips at the top of the bar, which is about $22 \mathrm{~mm}$ above the bottom of the chimney. As is shown in curve A of Fig. I, this is not high enough to give the maximum candlepower, and at this height small changes cause relatively large variation of candlepower. 
At the Bureau it has been considered important to retain the advantage given by using the maximum candlepower, and incidentally to adhere to the original manner of operating the lamps. The practice has therefore been definitely adopted of first determining the height of flame which gives the maximum candlepower for a given lamp, and then standardizing the lamp with the flame at that height. With American lamps the maximum is usually obtained when the top of the flame is nearly a centimeter above the bar. A line is marked on the window to show the height used, and the fact is stated in the certificate furnished with the lamp. The candlepower thus obtained is usually from one-half per cent to I per cent higher than would be given if the flame were set to the top of the bar.

The necessity of waiting a sufficient time after lighting the lamps before making measurements was emphasized in the earlier papers, where curves were given showing the variation of candlepower with time

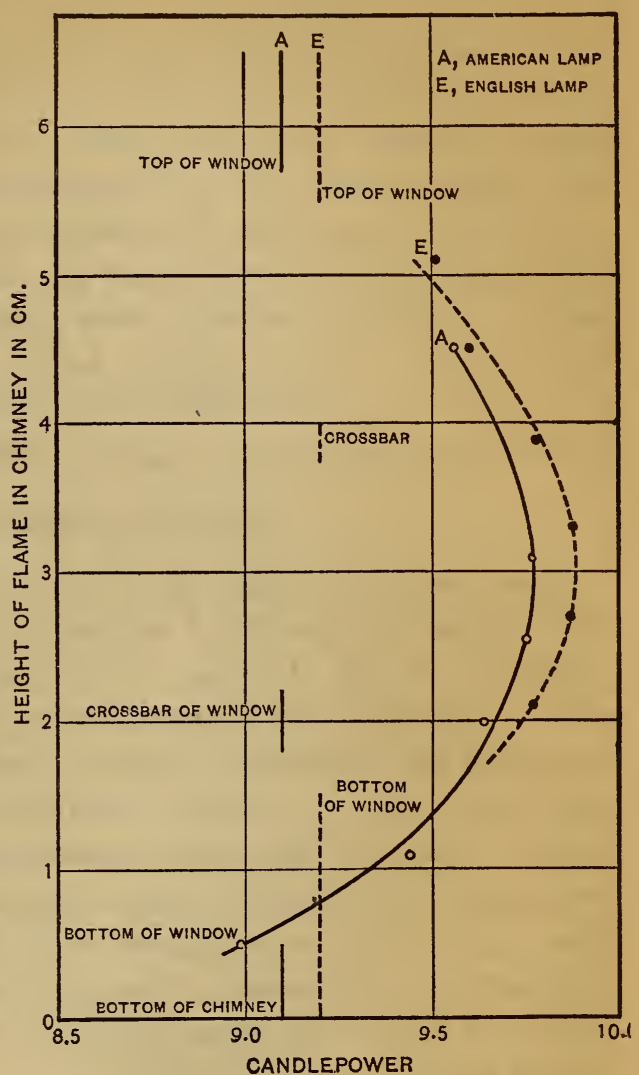

Fig. 1.-Variation of candlepower of pentane lamps with height of flame after lighting for English and American lamps. It is important to note that the candlepower rises rapidly at first, going above the normal, and then settles back to a fairly constant value. Considerable attention has been given to the measurement of the variations in temperature in various parts of the lamp which accompany these changes in candlepower. The details of the 
measurements will not be given here, but it may be said that they have strengthened the conviction that most of the change in candlepower caused by variation in conditions of operation may be attributed to the air circulating system and the variations in the flow of air which arise from changes in the relative temperatures of parts of the lamp. There is a slow change of temperature for a considerably longer time, but the candlepower is practically constant after 30 minutes in the case of the old style American lamps and after 20 minutes with the newer lamps. The excess of the maximum over the final candlepower is about 3 per cent and 2 per cent, respectively, for the two types. Lamps of the English type run from I per cent to $\mathrm{I} / 2$ per cent high at the maximum and may be considered constant after I 5 minutes burning. The smaller heat capacity of these lighter lamps, which allows them to reach a steady state sooner, seems also to make them more susceptible to variations caused by changing drafts.

\section{BASIS OF STANDARDIZATION}

The fundamental unit in terms of which lamps are certified is the international candle ${ }^{4}$ as maintained by the primary electric standards of the Bureau. The standards actually used in tests are a group of seven carbon lamps operated at low voltage so as to match the pentane in color. Since the flame is much redder than the ordinary electric standards the calibration of these special standards has taken considerable labor to insure that no important error be introduced because of this color difference. The group has been compared with the Bureau's regular working standards in three series of measurements by a number of different observers, under the direction of Dr. Middlekauff, and the average values have been as follows:

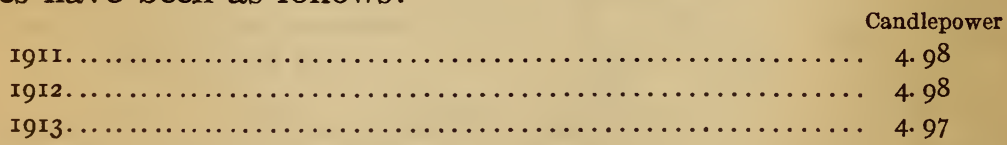

It appears therefore that the uncertainty in the value of these standards can not be very great. As a check on their permanence another group carefully compared with them is preserved and 
used only for checking the working standards. A similar group has also been prepared to be sent to England in order to obtain a direct comparison between the standards of the National Physical Laboratory and those of the Bureau operated at the color of the pentane flame.

To obtain the normal candlepower of the flame corrections are made for the effects of atmospheric moisture and pressure. These corrections will be considered in a separate section, since they must be used whenever it is desired to obtain absolute candlepower values with a flame standard. As a check against the introduction of errors by other conditions, such as poor ventilation, which might affect the flames but not the electric standards, a pentane lamp of known candlepower is always included in test runs.

\section{NUMBER OF MEASUREMENTS}

The number of measurements made on each test lamp in the course of standardization depends somewhat on the consistency of the results obtained. Usually each lamp is placed on the photometer about six times, and each time 4 measurements are made, each consisting of 25 to 40 settings of the photometer. The candlepower for each measurement is worked up separately, and if the average deviation of these values from the final mean is not materially greater than one-half per cent, and the values obtained for the check lamp run in the test are also normal, the test is considered satisfactory. If these conditions are not fulfilled, further measurements are made until it is believed that the mean candlepower of the lamp is sufficiently well determined. The candlepower is certified to the nearest tenth of a candle unless the average of test results falls very nearly halfway between tenths, in which case a subscript 5 is given in the hundredths place; this is written as a subscript to indicate that it is considered not as definitely established but merely as representing the average of test results.

\section{ACCURACY OF VALUES}

With all the precautions taken it is believed that the values certified for the lamp are correct within I per cent; that is, that under similar conditions the lamps should give average results 
within I per cent of those certified. It has occasionally happened that a second test on a lamp has given a result fully i per cent different from the value originally certified. The result obtained from a single time on the photometer sometimes departs as much as 2 per cent from the mean, but the maximum deviation is seldom as great as this. As for the permanence of the calibration no evidence has been obtained indicating any appreciable change with time. For the Bureau's two Chance lamps, which are regularly used as checks on tests, the average candlepowers found in I9Io were 9.87 and 9.89 ; the averages for the first six months of I9I3 have been 9.90 and 9.87 .

Conditions in different laboratories are not likely to be exactly the same, and in order to depend on reproducing values in different places as closely as I per cent one would probably need to give some care to reproducing conditions of operation. It would seem, however, that under any reasonably good conditions the difference ought to be well within 2 per cent, for, using good pentane and correcting for atmospheric moisture and pressure, it is difficult to produce that much variation in candlepower by any intentional change of conditions except vitiation of the air or incorrect flame height.

\section{GENERAL DIRECTIONS FOR USE OF PENTANE LAMPS}

It is hardly practicable to give here detailed directions as to the exact procedure to be followed in any case, but attention may be called in a general way to some precautions which should be taken in using the lamps. Many of the details of adjustment and operation which have already been discussed will be merely mentioned here. The best results will presumably be obtained by following the same methods in operating a lamp as were used in standardizing it. If the lamp to be used has been standardized at the Bureau, a reference to the preceding pages will answer most questions as to proper procedure. If the value of the lamp has been assigned by another laboratory, such questions should usually be referred to that laboratory. 


\section{VENTILATION AND EFFECTS OF VITIATION OF AIR}

Since all flames depend upon combustion it is to be expected that their intensity will vary with the proportion of oxygen and of other constituents in the air supplied to the gaseous fuel of the flame. To maintain a flame in a constant condition requires, therefore, not only uniform fuel, but also a uniform proportion of oxygen in the air supplied to the flame. Good ventilation is consequently desirable for all work with flames, and is indispensable where lamps of other kinds are to be compared with a flame standard. The quantity of air which must be supplied depends largely on the size and number of flames in the room and also on the method of ventilating. The flames themselves set up currents of air, and if possible these currents should be utilized to remove immediately from the room all the vitiated air coming from the lamps. A hood placed above the photometer with a rising pipe to lead the warm air out of the room is most effective.

If the gases from the flames are allowed to diffuse into the room and are simply diluted by the air entering, a much larger amount of fresh air will be needed. In such a case it has been estimated ${ }^{5}$ that to keep the carbon dioxide content of the air down to 6 parts in 10 000, 3000 cubic feet of fresh air per hour must be supplied for each person in a room. A committee of the American Gas Institute ${ }^{6}$ has on this basis estimated that 36900 cubic feet of air per hour should be supplied for a photometer room where two persons work with a pentane lamp and a 5 -foot gas flame, since in the production of carbon dioxide the gas flame is approximately equivalent to six persons and the pentane lamp to four.

In a room where air enters at the bottom and escapes at or near the top the quantity estimated as above (about $\mathrm{r} 2000$ cubic feet per hour for a pentane lamp) is probably ample for any purpose, and if care is taken to allow direct escape of the flame gases a much smaller amount is sufficient.

Some caution is necessary in making calculations based on the quantity of carbon dioxide in the air. Experimental determina-

\footnotetext{
Kent: Mech. Eng. Pocketbook, x912 ed., p. 654. ${ }^{6}$ Proc. Amer. Gas Inst., 2, pp. 481-482; 1907.
} 
tions of the effect on flames have sometimes been made by adding carbon dioxide to the air, and it must be remembered that the dilution of the air by a quantity of added $\mathrm{CO}_{2}$ has relatively little effect as compared with the conditions arising when the same amount is formed in the process of combustion, using up the oxygen of the air. In the formation of 5 cubic feet of $\mathrm{CO}_{2}$ by the combustion of pentane, for example, 8 cubic feet of oxygen are used. Since the abstraction of I cubic foot of oxygen has practically the same effect on the composition of the air as the addition of 5 cubic feet of inert gas, it is evident that the reduction in the amount of the active oxygen is of much greater importance than the increase in the diluting gases. The effect produced on the Hefner lamp by adding I part of $\mathrm{CO}_{2}$ to Iooo of air, according to Liebenthal, ${ }^{7}$ is a reduction of 0.7 per cent in the candlepower, but the generation of the same proportion of $\mathrm{CO}_{2}$ by combustion and breathing in a room has been found ${ }^{8}$ to be accompanied by a decrease of 2.2 to 3 per cent in the Hefner, the pentane lamp, and other flames. In general, the effect depends on the manner of production of the $\mathrm{CO}_{2}$, since the greater part of the decrease is due not to the presence of $\mathrm{CO}_{2}$ but to a deficiency of oxygen. Determinations of the amount of $\mathrm{CO}_{2}$ in the air, consequently, do not furnish sufficient data for exact correction for vitiation of the air, but are useful in that they enable one to judge the effectiveness of the ventilation.

In many cases, however, determinations of $\mathrm{CO}_{2}$ are not practicable and the effectiveness of the ventilation must be judged by other means. When facilities are available for setting an electric lamp repeatedly to the same current a direct test can be obtained by making a series of measurements of the electric lamp against the pentane and finding whether the latter shows a gradual decrease after it should have reached a constant value. Another test which is as definite as determination of the carbon dioxide and far more easily carried out is afforded by careful measurement of the humidity, for the processes which use up oxygen add water as well as $\mathrm{CO}_{2}$ to the air. If the water vapor regularly increases

\footnotetext{
${ }^{7}$ Zs. f. Instrumentenkunde, 15, p. $157 ; 1895$.

8 C. C. Paterson, Collected Researches, National Phys. Lab., 3, p. 49; 1908. Butterfield, Haldane, and Trotter, Jour. Gas Light, 115, p. 290, 1911, and Amer. Gas Light Jour., 95, p. 145, 1911; also unpublished tests of Bureau of Standards.
} 
by an appreciable amount during the operation of the lamp, the ventilation is not satisfactory. An increase of I liter of water vapor per cubic meter of air, when caused by poor ventilation, is quite regularly accompanied by such vitiation as to cause about 2 per cent decrease in the candlepower of flames, in addition to the 0.6 per cent decrease caused by the water vapor itself.

In designing ventilating inlets ample capacity should be provided to allow a slow flow of air into the room in order to avoid drafts which would cause unsteadiness of the flame. Similarly, if a hood is used as recommended, the outlet must be so arranged that the flow of air into the hood shall not be too vigorous. Troublesome drafts are apt to arise if the walls of the photometer room differ much in temperature from the air. It is therefore desirable that none of them shall be exterior walls of the building. If such walls are unavoidable, they should be either jacketed with nonconducting material or covered by a false wall with an air space. If possible, the room should be so free from drafts that the flame will burn steadily without other protection than the necessary photometric screens. If further protection from drafts is necessary, a screen of the form described on page 395 should be used.

\section{PREPARATION OF LAMP}

In preparing the lamp for use one should observe the following details: Centering of chimney over the burner, height of the chimney above the burner, direction in which the mica window is turned, amount of pentane in the saturator, height, orientation, and leveling of the lamp, and its distance from the middle point of the bar or some other definite point on the scale. It is advisable, at least in the beginning, to check the last two adjustments by direct measurement, as described on pages 396 and 397 . If then the plumb bobs (or the level and bob) are found to be correct, they may be used thereafter.

The saturator should be from one-third to two-thirds full of pentane at starting, and the height of the liquid as seen against the window of the saturator should never be less than $3 \mathrm{~mm}$ (oneeighth of an inch). Since pentane is very volatile and inflammable, and the heavy vapor flows downward, it is extremely haz- 
ardous to fill a lamp while it is burning. This should never be attempted under any circumstances, and it should be an inviolable rule of the laboratory that no pentane in an open vessel be brought near any flame.

Immediately before the lamp is lighted the height of the chimney should always be tested with the gauge, and occasionally the gauge itself should be measured to see that it remains $47 \mathrm{~mm}$ long.

\section{OPERATION}

To light the lamp open first the saturator inlet cock, then holding a lighted match over the burner open the outlet cock gradually. If the lamp has a regulating cock near the burner, the saturator cocks may both be opened and the flame controlled by this regulating cock. If no such cock is provided, the saturator outlet cock is used for regulation. Usually on opening the cocks the vapor will flow so that the lamp will light, but it is sometimes necessary to start the flow of vapor by blowing gently into the saturator inlet. Sometimes also the lamp at first burns with a small blue flame because the heavy vapor has flowed down into the burner and prevents the normal circulation of air from starting. If this happens, shut off the cocks, and blow up into the outer chimney to start the air, keeping below the burner to avoid the small burst of flame which may result if the flame has not entirely died out in the tip. The lamp will then light normally. After it is lighted see that the conical hood around the flame is so placed that the whole flame is visible from the photometer disk.

The flame should be kept at approximately the correct height, and no measurements should be made until the lamp has burned I 5, 20, or 30 minutes, according to whether it is of the English type or of the new or old American forms. Unless otherwise specifically stated in the lamp certificate for the American lamps the proper flame height is obtained when the tips are just above the crossbar of the window, while in English lamps the flame should extend halfway up the lower window. As already stated, American lamps standardized recently at the Bureau of Standards have a line on the window to which the top of the flame is to be set. After the lamp has burned a few minutes such changes in 
flame height as occur are gradual, and except in the most careful work it is not necessary to have a special observer to watch the flame.

The lamp is extinguished by shutting off the saturator cocks. When it is not in use both cocks should be kept closed, and a cap should be placed over the burner to prevent injury to it or the collection of dust in the passages. All parts of the lamp should be kept well blackened.

\section{PENTANE-PREPARATION, TESTING, AND USE}

\section{PREPARATION AND TESTING}

The directions of the Gas Referees for the preparation and testing of pentane are as follows:

Preparation.-Light American petroleum, such as is known as Gasoline and used for making air-gas, is to be further rectified by three distillations, at $55^{\circ} \mathrm{C}$., $50^{\circ}$, and $45^{\circ}$, in succession. The distillate at $45^{\circ}$ is to be shaken up from time to time during two periods of not less than three hours each with one-tenth its bulk of (I) strong sulphuric acid, (2) solution of caustic soda. After these treatments it is to be again distilled, and that portion is to be collected for use which comes over between the temperatures of $25^{\circ}$ and $40^{\circ}$. It will consist chiefly of pentane, together with small quantities of lower and higher homologues whose presence does not affect the light of the lamp.

Testing. - The density of the liquid pentane at $15^{\circ} \mathrm{C}$. should not be less than 0.6235 nor more than 0.626 as compared with that of water of maximum density. The density of the pentane when gaseous, as compared with that of hydrogen at the same temperature and under the same pressure, may be taken. This is done most readily and exactly by Gay Lussac's method, under a pressure of about half an atmosphere and at temperatures between $25^{\circ}$ and $35^{\circ}$. The density of gaseous pentane should lie between 36 and 38 .

Any admixture with pentane of hydrocarbons belonging to other groups and having a higher photogenic value, such as benzene or amylene, must be avoided. Their presence may be detected by the following test: Bring into a stoppered 4-ounce bottle of white glass ro cc of nitric acid, specific gravity r.32 (made by diluting pure nitric acid with half its bulk of water); add I cc of a dilute solution of potassium permanganate, containing o.I gram of permanganate in $200 \mathrm{cc}$. Pour into the bottle $50 \mathrm{cc}$ of the sample of pentane, and shake strongly during five successive periods of 20 seconds. If no hydrocarbons other than paraffins are present, the pink colour, though somewhat paler, will still be distinct; if there is an admixture of as much as one-half per cent of amylene or benzene, the colour will have disappeared.

For the benefit of those who are not chemists it should be said that this last test should always be preceded by a blank test to $35^{26} 5^{\circ}-\mathrm{r} 4-7$ 
check the purity of the reagents, for if the nitric acid is not pure it will decolorize the permanganate. The acid should be kept in the dark to avoid deterioration.

The pentane used at the Bureau is tested with respect to purity and density of the liquid. The density is conveniently determined by a hydrometer carrying a thermometer. The correction for temperature is important, being about o.oor per degree centigrade or 0.00055 per degree Fahrenheit.

\section{CHANGE DURING USE, AND CORRECTION DETERMINED BY DENSITY}

In the sealed ether cans in which pentane is now purchased no difficulty has been found in keeping a supply which fulfills the specifications when the cans are opened, but the more rapid evaporation of the lighter fractions raises the density as the fuel is consumed in the lamp. It is quite impracticable to work with pentane within the limits prescribed, for the density is certain to be too high before one-tenth of the pentane is consumed; in fact, the density usually reaches 0.635 when a little over half has been used.

The directions of the London Gas Referees are to empty the saturator completely at least once a month when three tests daily are made, but this appears to be decidedly too long a period. The residue of higher density gives a slightly higher candlepower than the fresh pentane. When repeated additions of fresh fuel are made, and the accumulated residue remains in the lamp, a mixture is obtained such that an appreciable change in candlepower may occur in a relatively short time. It therefore appears desirable to empty the saturator after it has been replenished only three or four times. It is not necessary, however, to discard the portions emptied out; if these are collected and not mixed with fresh pentane, fairly reliable results can be obtained by using the residues thus collected, making a suitable correction determined by the density. Considerable attention has been given to the determination of such a correction, and the results of the measurements made are shown in Fig. 2. The relation between candlepower and density is probably not really linear, but for present purposes may be assumed so. It will be seen that the 
change in candlepower averages about $\mathrm{I}$ per cent for an increase of 0.01 in the density of the fuel. Samples of pentane from different sources which have been initially high in density have also given results agreeing fairly well with this rule. Consequently, it appears to be allowable to apply such corrections in many cases where the expense for pentane can thus be cut down materially without any considerable sacrifice of accuracy.

In the standardization of lamps at the Bureau the pentane used is always kept below 0.635 in density. The values certified may

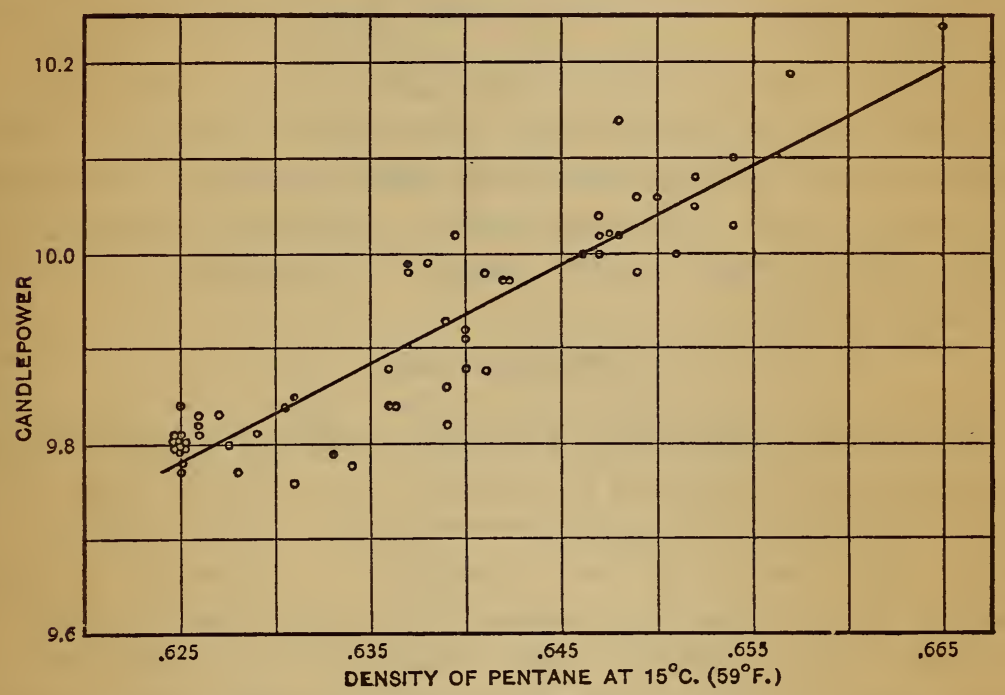

Fig. 2.-Variation of candlepower of pentane lamps with density of pentane

therefore be considered as correct for a density of 0.630 . No correction need be made for pentane below 0.635 , but above that density correction is desirable. For example, if the pentane used runs up to 0.650 , the candlepower obtained is presumably 2 per cent above that certified for the lamp, and this density is likely to be reached if a gallon of pentane is used without removing the residue from the saturator.

It should be noted that the above discussion refers to pentane which is initially fairly pure, as shown by the permanganate test. If the fresh pentane contains impurities, these are usually con- 
centrated by the fractional distillation in the lamp, and the result may be an increase in candlepower greater than that given above.

\section{EFFECTS OF ATMOSPHERIC CONDITIONS}

It is usually assumed that the effect of all atmospheric conditions is the same on all flames and is therefore automatically corrected when flames are compared with flames, but it is sometimes necessary to know the amount of departure from the normal value, as when flame standards are compared with electric lamps. The dependence of flame intensity on the composition of the air is so complicated a matter that the determination of exact corrections for vitiation of the air is impracticable, and when observations are to be reduced to normal values good ventilation is indispensable so that no such corrections shall be needed. With pure air, however, there are considerable variations in candlepower because of variations in the amount of moisture and in the barometric pressure.

\section{TEMPERATURE}

Temperature might also be expected to affect the pentane lamp appreciably, but nearly all investigators have agreed that within the usual laboratory range it does not do so. In the work at the Bureau there has so far been available no means of changing temperature and humidity independently, and the effects of the two can not be separated with certainty. The results obtained can be represented about equally well by assuming that temperature has no effect or by making a small correction for temperature and using a correspondingly different factor for water vapor. In accordance with the usual custom the former practice will be followed, and the present discussion will be limited to the effects of barometric pressure and of water vapor.

\section{BAROMETRIC PRESSURE}

In general, flames give less light when the barometric pressure is low, but the effects on different sorts of lamps are markedly different. For the ro-candlepower pentane lamp a change of 0.6 per cent per centimeter (I.5 per cent per inch) was found at the 
Physikalisch-Technische Reichsanstalt, ${ }^{9}$ while the result obtained at the English National Physical Laboratory ${ }^{10}$ is 0.8 per cent per centimeter ( 2 per cent per inch), and more recent work ${ }^{11}$ in England has verified the latter value for pressures near the normal. Various determinations at the Bureau have not been consistent, chiefly because of the small range of pressure obtained. The results for the determinations which should have been most reliable have varied from 0.6 to 0.8 per cent, and consequently the English value, 0.8 per cent per $\mathrm{cm}$. has been used. ${ }^{12}$ The chart of deviations given in Fig. 3 is plotted on this basis.

\section{WATER VAPOR}

Water vapor in the air lowers the intensity of the flame; the effect has been found to be proportional to the amount of water present. This amount is expressed in liters $(h)$ of water vapor per cubic meter of dry air; in other words, in parts of water vapor per 1000 parts of dry air. The pressure $(e)$ of the water vapor is determined by means of a hygrometer (preferably of the ventilated type) using tables adapted to the particular type of hygrometer. If the barometric pressure is represented by $b$,

$$
h=\frac{e}{b-e} \times \text { I000. }
$$

A normal value $(n)$ for the amount of water vapor must be chosen more or less arbitrarily. Then, if $I_{n}$ is the normal intensity of a given flame (that is, the intensity when there are $n$ liters of water vapor per cubic meter of dry air), the intensity $I$ at any particular time is given by the equation

$$
I=I_{n}[I+(n-h) a] \text {. }
$$

The normal proportion of water vapor has been fixed at 8 liters for the pentane lamp; the correction factor $(a)$ has been several

\footnotetext{
'J.f. Gas. u. Wasser., 49, p. 56r; 1906.

${ }^{10}$ Electrician (London), 53, p. 751, 1904; J. Inst. of Elect. Eng., 38, p. 271, 1906-7; J. Gas Light., 99, p. 232, 1907; N. P. I., Collected Researches, 3, p. 49, 1908.

11 Butterfield, Haldane, and Trotter: J. Gas Light., 115, p. 290, I91 ; and Amer. Gas Light J., 95, p. 145, I9II.

12 In the Transactions of the Illuminating Engineering Society, 5, p. 776, 1910, it was inadvertently stated that the fact or 0.6 is used, when it should have been said that this factor was obtained from the data then reported on.
} 
times determined, but the agreement between results in different laboratories is not close. These determinations were rather fully discussed in one of the earlier articles mentioned; ${ }^{13}$ it is sufficient to recall here that the National Physical Laboratory ${ }^{14}$ found $a$ to be 0.0066 , whereas the Reichsanstalt ${ }^{14}$ obtained 0.0055 , and the Bureau of Standards 0.0057 . The more recent English tests ${ }^{14}$ have given 0.00625 .

The method of testing lamps at the Bureau furnishes continual data for the redetermination of the correction factor, and complete calculations have been made using the results up to the beginning of the present year on all lamps whose tests have included a range of 5 liters of water vapor or more. To reduce the labor of calculation the values obtained each time a lamp is placed on the photometer have been grouped together. Some insignificant changes in the data published in I9Io have been made to correct for slight errors introduced by the barograph then used, and the revised results are given in Part I of the table below. These data include 628 groups of sets, or about 30 ooo individual settings of the photometer. The data obtained from later tests are summarized in Part II of the table; they represent about 2300 groups of sets, or perhaps 75000 individual photometer settings.

Water Vapor Correction Factors

I. OBSERVATIONS OF 1910

\begin{tabular}{|c|c|c|c|}
\hline Lamp & $\begin{array}{c}\text { Times } \\
\text { on photo- } \\
\text { moter }\end{array}$ & Weight & Factor $a$ \\
\hline Chance $116 \ldots .$. & 74 & 174 & 0.00568 \\
\hline Chance $118 . . . . . . . . .$. & 23 & 22 & .00565 \\
\hline 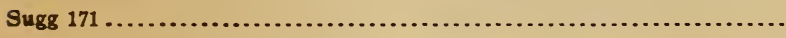 & 62 & 130 & .00565 \\
\hline 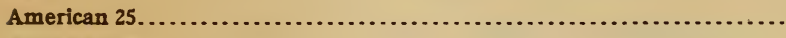 & 16 & 11 & .00584 \\
\hline 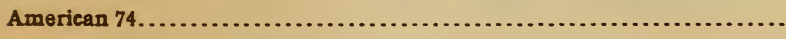 & 19 & 48 & .00564 \\
\hline 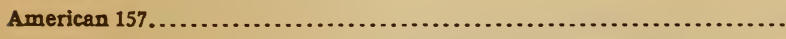 & 11 & 8 & .00581 \\
\hline 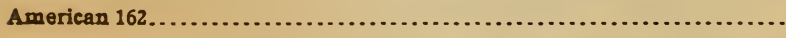 & 7 & 9 & .00572 \\
\hline Weighted mean value of $a$. & & & .00567 \\
\hline
\end{tabular}


Water Vapor Correction Factors-Continued.

II. OBSERVATIONS OF 1911-12

\begin{tabular}{|c|c|c|c|}
\hline Lamp & $\begin{array}{c}\text { Times } \\
\text { on photo- } \\
\text { meter }\end{array}$ & Weight & Factor e \\
\hline Chance $116 . . . . . . . . .$. & 135 & 226 & 0.00586 \\
\hline 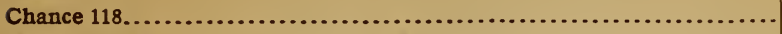 & 177 & 339 & .00552 \\
\hline 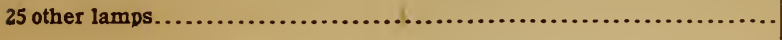 & 264 & 269 & .00569 \\
\hline Weighted mean value of $a .$. & & & .00567 \\
\hline
\end{tabular}

In assigning weights to individual lamps, allowance was made both for the number of times on the photometer and for the range of humidity covered. Since ranges as small as 5 liters were included, giving a total variation of only 3 per cent in these cases, and some of the lamps were on the photometer only six times, the results from individual lamps can not be expected to agree very closely. However, only two lamps gave a value for $a$ below 0.0050 , and the highest value obtained was 0.0066 . The mean result checks the former one even more closely than could be expected, and there seems to be no room for doubt that, at least in the Bureau laboratory, the effect is very definitely and consistently represented by a factor of 0.57 per cent per liter of water vapor. This factor has been used in plotting the chart which is reproduced in Fig. 3 .

\section{CHART OF DEPARTURES FROM NORMAL VALUE}

This chart has been so plotted that the departure of a lamp from the normal value can be read directly from it when the barometric pressure and the readings of the wet and dry bulb thermometers of a ventilated hygrometer are known. The hygrometer may be either a sling psychrometer such as is used by the United States Weather Bureau or a mechanically ventilated instrument like the Assmann psychrometer. If an ordinary stationary hygrometer is used, the covering of the wet bulb should be only one thickness of very thin material, and the reading should be taken at the lowest point to which it can be brought by vigorous fanning. 


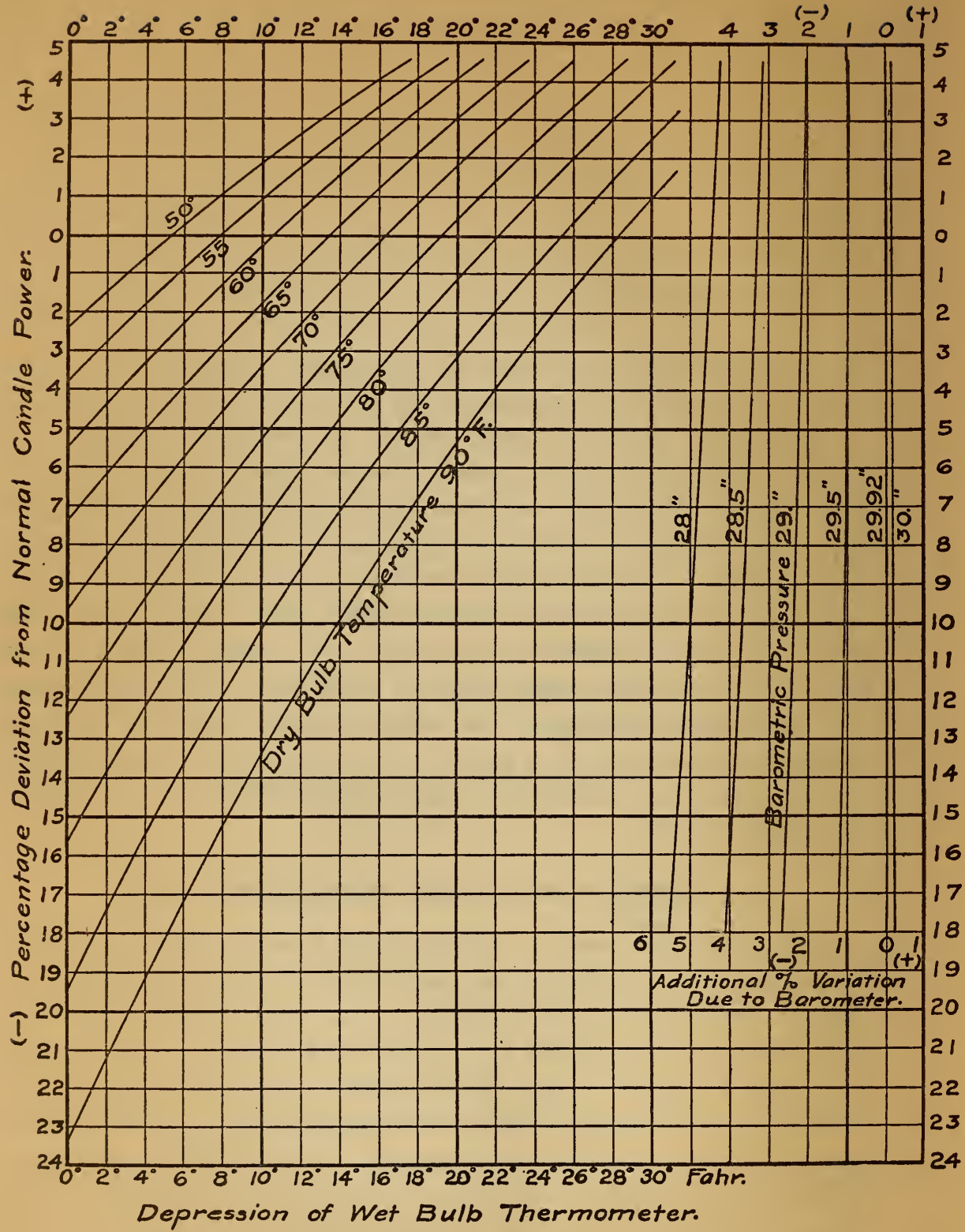

Fig. 3.-Variations of candlenower of pentane lamps with humidity and barometric pressure 
The curves at the left of the chart give the percentage deviation from normal candlepower which corresponds to given temperature and wet-bulb depression when the barometric pressure is normal, which for the pentane lamp is $760 \mathrm{~mm}$ (29.92 inches). When the pressure is different from this the additional deviation can be found from the curves at the right, as follows: First read off the deviation in the regular way as if the barometer were normal, and note this; then from this point pass horizontally across the sheet to that curve at the right which represents the actual pressure. Vertically above or below the point at which this curve is reached will be found the amount to be added to the deviation as read from the first curves. This added amount is made up chiefly of the direct effect of pressure on the candlepower, but it includes also a proper allowance for the fact that the amount of water vapor which corresponds to a given pair of bulb readings depends somewhat on the barometric pressure.

The chart is plotted for the pentane lamp, but so far as we know it may be applied to other flames without introducing serious errors. It would certainly be justifiable to measure gas flames, for instance, with electric standards and to correct the observed candlepowers to obtain normal values according to the chart.

\section{VARIATIONS OF HUMIDITY IN THE UNITED STATES}

In order to give some idea of the amount of variation in water vapor which occurs from season to season data calculated from the records of the Weather Bureau which give the state of the outdoor air have been plotted in Fig. 4. In general the amount of moisture is small in winter and large in summer; the average for May and for October is practically the same as for the whole year. The variation from day to day is often great, especially in the spring and fall, but the monthly averages show considerable regularity from year to year. The curves are plotted from the averages of observations for five years.

The normal values of humidity adopted in Europe are lower than the average for nearly all parts of the United States; consequently, the average of uncorrected candlepowers of flame stand- 
ards in this country runs somewhat lower than the normal intensities. The following table gives the average amounts of water vapor at several cities for the period of five years plotted in Fig. 4. The last column gives the corresponding departure

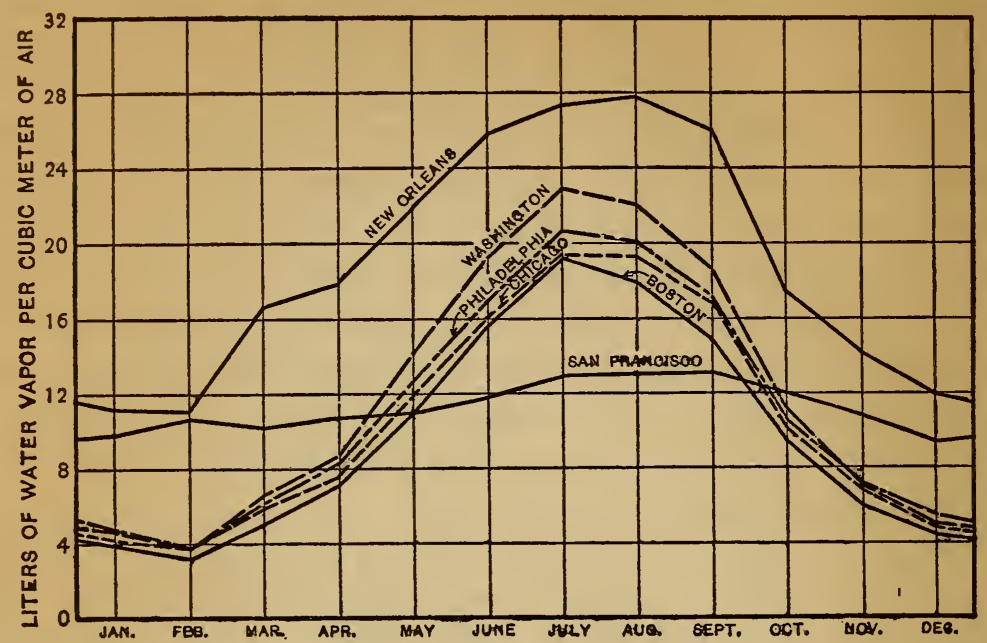

Fig. 4.-Average water vapor content of the air at various cities, 1904-1908

of a pentane lamp from its normal value, which is practically the percentage of difference between the nominal and the actual average candlepower of any source which is measured by the lamp.

Average Water Vapor and Pentane Candlepower in the United States

\begin{tabular}{|c|c|c|}
\hline Place & $\begin{array}{l}\text { Average water } \\
\text { vapor (liters } \\
\text { per cubic } \\
\text { meter) }\end{array}$ & $\begin{array}{c}\text { Per cent } \\
\text { departure of } \\
\text { pentane lamp } \\
\text { from normal } \\
\text { value }\end{array}$ \\
\hline Boston ............. & 9.9 & 1.1 \\
\hline Omaha ....................... & 10.3 & 1.3 \\
\hline Chicago.............................. & 10.6 & 1.5 \\
\hline Philadelphia .................. & 11.2 & 1.8. \\
\hline San Francisco................... & 11.3 & 1.9 \\
\hline 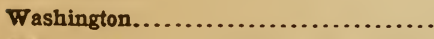 & 12.0 & 2.3 \\
\hline New Orleans ..................... & 19.1 & 6.3 \\
\hline
\end{tabular}




\section{SUMMARY}

In this paper we have attempted to describe fully the method of testing pentane lamps at the Bureau of Standards, to give brief general directions for the use of the lamps, to discuss more fully the question of fuel, and to furnish data on the effects of pressure and moisture in a form which may be useful for those who have occasion to reduce observations on flames to normal candlepower values. Such new data as has been introduced has been obtained in the laboratories of the Bureau, and our acknowledgments are due to Dr. Rosa, under whose direction the work has been carried on, and to Mr. G. J. Schladt, who has assisted in most of the tests.

WASHINGTON, August 2, I9r3. 



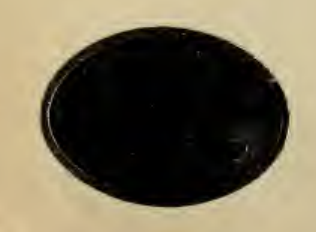


